\title{
KONSEP DAN PROSES SOSIALISASI DALAM AMDAL DAN PEMBANGUNAN (Studi kasus: Pembangunan Jembatan layang Lubuk-Buaya Padang)
}

\author{
Mulyadi $^{1}$ dan Mery Teresia ${ }^{2}$ \\ ${ }^{1}$ Dosen Fak. Teknik UMSB \& Mahasiswa Pascasarjana UNP Padang \\ ${ }^{2}$ Dosen ATG Padang
}

\section{ABSTRACT}

Beverement aims to change from a condition to a better condition, however this effort â $s 0$ a negative (risk) impact on the environment and includes the communities within In the effort of environmentally safe development activities, almost every potential or ginififant development activity on environmental damage is required to conduct an Envirenmental Impact Analysis (EIA). Risk reduction efforts or damage to the environment in who the object of development that is accommodated in the form of socialization, is stil: not optimal. Is socialization only limited to introduce EIA activity process to society ङr secialization also introduce and also involve society in development activity. Sociatization is a significant factor in creating a successful process of development activities and EIA activities and not merely introducing but further involving the community in the overall development process. Socialization activity is an activity of interizization of new culture (development) into society life or change society into 唯vetioment purpose. Bringing people together to engage especially those directly affected 6y ativities in the development plan will be able to act as agents of change in the tevelepment. An important or significant role is the socialization activity is to minimize the orap between the planned development activities to be conducted with the community. The research was conducted on several socialization of EIA study and analyzed through incert formulation and socialization process in change theory.

艮e

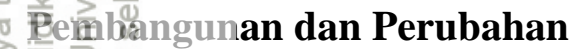

\section{PENDAHULUAN}

Konsepsi pembangunan mencakup berbagai aspek termasuk aspek-aspek spasial, Watur lebih didominasi oleh aspek ekonomi, sebab aspek ini dapat membuktikan dan 的的角uskan keberhasilan. Pembangunan dengan pendekatan ekonomi dapat dirumuskan secarakonsepsional (Nasution, 2007) dengan melibatkan pertimbangan dari aspek sosial dartligkgkungan serta dilaksanakan secara transparan dan adil. Dari aspek sosial, dilakukan Letigan mempertimbangan aspirasi masyarakat dan meningkatkan fungsi danperanan Hentale Dari aspek lingkungan, lebih menekankan fungsi Lelestân lingkungan alami guna keberlanjutan hidup umat manusia. Terakhir adalah

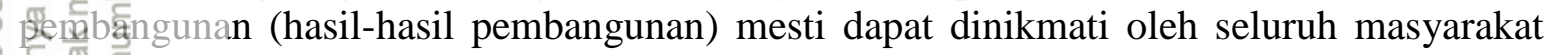
secaratil dan tidak terbatas batas ruang dan waktu.

Dilihat dari sudut makna pembangunan sangat bagus sekali bahwa Pe 1 ba deng a

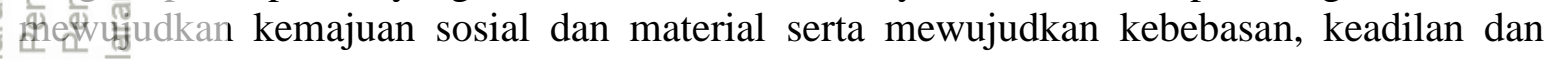
kiaditâs hidup bagi seluruh masyarakat. Pembangunan dapat dipandang (Kleinjans dalam - Nasution, 2007) sebagai suatu proses pencapaian pengetahuan dan keterampilan 
baru, perluasan wawasan manusia, tumbuhnya suatu kesadaran baru, meningkatnya semangat kemanusiaan dan suntikan kepercayaan diri. Pembangunan memberikan makna kepada suatu proses perubahan dari suatu kondisi menuju pada yang kondisi yang lebih Baik lagi dan proses akan terus berlangsung. Berbeda dengan Kleinjans yang lebih menitik Geratkan kepada aspek sosial-kultural, Shoemaker (Nasution, 2007) memandang Rembangunan sebagai suatu proses perubahan sosial dengan ide-ide baru yang

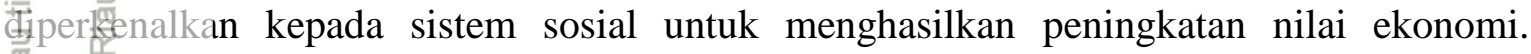
fembangunan lebih merupakan perubahan sosial (sosial-ekonomi) untuk meningkatkan Fendatan perkapita, peningkatan taraf kehidupan yang lebih tinggi dan peningkatan tersebitit dapat dicapai dengan metode produksi modernisasi dalam semua tingkat sistem sociali masyarakat.

$\subseteq$ Pemikiran tentang pembangunan (Nasution, 2007) mengidentikan pembangunan dengân perkembangan, modernisasi, industrialisasi, dan westernisasi, dimana dasardasare pemikiran ini mengandung unsur perubahan. Proses perubahan dalam קृembangunan (Alexander dalam Nasution, 2007) mencakup seluruh proses system solia. politik, ekonomi, infrastruktur, pertahanan, pendidikan dan teknologi, Felengagaan, dan budaya. Terminologi proses perubahan (pembangunan) dapat juga Gitemkikan dalam wujud konsep sistem yaitu transformasi, seperti yang dikemukakan Â \$o siat dan budaya untuk meciptakan berbagai aspek kehidupan masyarakat. Proses transformasi ekonomi, sosial dan budaya sangat bersifat umum dan ini dapat dirinci

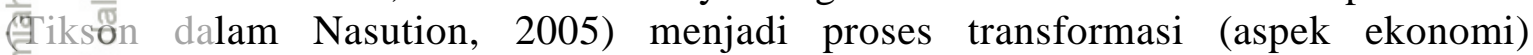
קeningatan dan pertumbuhan produksi di sektor industri dan jasa, yang dapat berkontribusi terhadap pendapatan. Transformasi sosial melalui pendistribusian Kemakmuran melalui pemerataan memperoleh akses terhadap sumber daya sosial-

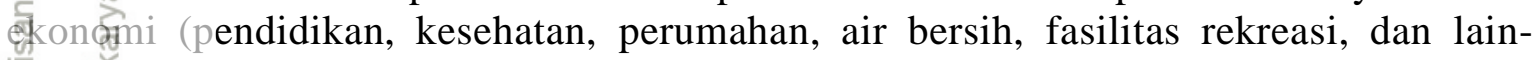
E-ain).

Meningkat kompleksitas kehidupan dalam berbagai aspek kehidupan, perubahan afau ôtransformasi terutama dalam dunia modernisasi sekarang telah memicu pertumbuhan ekonomi semakin tinggi. Peningkatan pertumbuhan untuk memenuhi ke butuhan manusia yang tidak terbatas, memberikan akibat kepada peningkatan proses Prdele Sid Go Gerbanding lurus terhadap dampak yang diakibatkan oleh produksi tersebut. rifangan peningkatan pertumbuhan ataupun pembangunan meletakan proses produksi SA (agogra dasi) disamping peningkatan pemenuhan kebutuhan/ kepuasan hidup manusia.

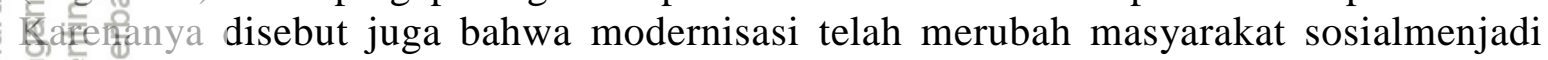
通a罗yarrakat konsumtif.

grosiatisasi

( teration semua kegiatan publik yang terkait dengan masyarakat selalu diawali ferig kegiatan sosialisasi. Ssosialisasi sebagai suatu proses interaksi (Vander, 1979) yang

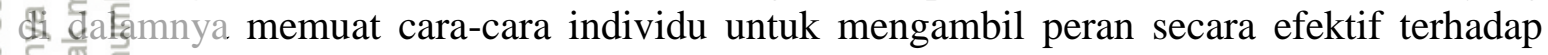

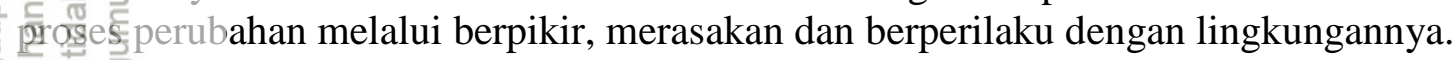
êtemorni, fisik (sumber daya alam atau SDA) dan manusia diintegrasikan guna mencapai (1) Kesejahteraan manusia (human well-being). Ketiga aspek ini memainkan peranan gang serbeda-beda yaitu aspek ekonomi berperan sebagai alat (tools) pembangunan, aspek fisis (SDA) berperan sebagai subjek pembangunan dan aspek manusia sebagai objek dari : pembraingunan. Pembangunan adalah mengintegrasikan ketiga peranan yang berbeda ini 
talam perubahan dan akan jadi lain proses integrasi dilakukan setelah proses perubahan berlangsung.

Pertumbuhan ekonomi dipacu yang berujung pada salah satunya adalah seningkatan infrastruktur, seiring dengan itu pembangunan fisik (mencegah dan 器engurangi proses degradasi) juga dilakukan melalui AMDAL dan UKL-UPL. Kedua 稆pek_ini hanyalah mencakup alat dan subjek pembangunan dan objek pembangunan belun tersentuh. Sementara kegiatan sosialisasi adalah proses interaksi ketiga aspek Pembangunan untuk mencapai kesejahteraan masyarakat/ manusia.

क Proses sosialisasi merupakan proses perubahan individu untuk membentuk diri sehinga sesuai dengan tingkah-laku serta belajar menjadi bagian dari lingkungan atau menj Erooledalam Syarif) berlangsung dalam tiga fase, yang disebut sosialisasi primer, sekunder dan Te्drsier. Fase primer berlangsung dalam keluarga, fase sekunder terjadi di luar lingkup keluafga, dan fase tersier terjadi ketika individu masuk dalam situasi sosial yang baru dalan masa kedewasaannya. Pembangunan dalam aspek manusia merupakan proses peruban individu mulai dari fase primer, sekunder dan tersier sehingga individu-individu Gapatomenyesuaikan diri dengan laju pembangunan yang (ekonomi dan fisik). Kegiatan Fembangunan fisik semestinya hanya menuntut untuk sosialisasi fase tersier, namun स्स्रlakatinya juga dihadapkan kepada perubahan interaksi kepada sosialisasi sekunder. Dalam kregiatan AMDAL/ UKL-UPL, masyarakat hanya diharapkan terjadi perubahan pada fase tersieñ namun adakalnya juga dituntut untuk sampai pada proses perubahan sekunder.

증 Masyarakat yang berada pada posisi belum mencapai perubahan pembangunan sebagaimana mestinya, sedang lingkungan telah mengalami proses pembangunan terutama aspek beingd Ketimpangan ini menjadi hambatan tersendiri dalam melakukan integrasi aspek遄pek ekonomi, fisik dan manusia dalam suatu proses pembangunan. Melibatkan 夜ansyakat untuk ikut serta dalam proses pembangunan merupakan tantangan tersendiri dalamproses perubahan.

i Keluarga sebagai unit terkecil dalam masyarakat mesti telah memainkan peranan ê. da Fam keluarga telah terdapat sistem-sistem perekonomian, kepercayaan, kekerabatan, peneli ikan, dan sistem-sistem inilah yang mesti mendapatkan perhatian agar individu siap

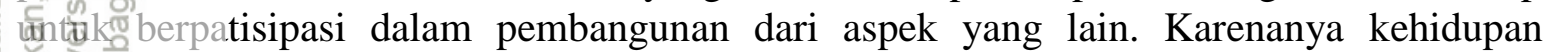
terarga dan berinteraksi bagi anggotanya, memegang fungsi sentral untuk mengontrol memacu pertumbuhan.

\section{Priteg}

政 perangkatan pendapatan income per capita (pendapatan per kapita). Pendapatan dapat Eerpeqan (Nasution, 2007) menjadi power/kekuatan dan dengan menjadi kemampuan Statu negara untuk meningkatkan pertumbuhan output yang dapat melebihi jerembuhan penduduk. Salah satu proses dari aspek pembangunan ekonomi yaitu Feiengatan proses industrialisasi. Kontribusi dari proses industry memiliki 倦ecenglerungan untuk melihat segi kuantitatif dalam pembangunan yang diuraikan

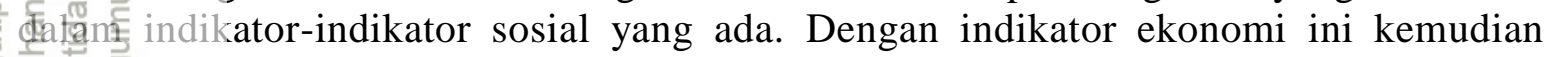
\$egerikan gambaran kemakmuran atau human well-being.

을 슬 Pembangunan dari aspek fisik guna memperoleh manfaat yang besar dari SDA ự 位e àgea kepada lingkungan. Orientasi pembangunan kemudian melahirkan orientasi baru - yaitu @iembangunan berkelanjutan (sustainable development) dengan melakukan perubahan 
Bembangunan namun tidak merusak atau mengurangi kerusakan lingkungan agar SDA Kabis dan dapat berlanjutan bagi generasi mendatang.

Pembangunan aspek manusia (sosial) tidak lain adalah bertujuan untuk mengkondisikan para individu agar mereka memiliki kemampuan untuk beradaptasi Gengan perubahan. Proses pembangunan ini merupakan pembangunan dalam 黉empersiapkan individu untuk berupa perubahan dari ketidakmampuan (human Ill-being) 覃enjafli individu-individu yang memiliki kemampuan untuk mengikuti perubahan dalam Pembangunan (human well-being).

Ketiga aspek pembangunan ini merupakan komponen pembangunan untuk proses perubshan yang tidak berdiri sendiri-sendiri (terpenggal-penggal). Saling ketergantungan cetiga aspek merupakan suatu rangkaian proses perubahan yang dapat menciptakan Trtegiasi. Ketiga aspek pembangunan ini dapat menjadi satu kesatuan dan saling 19empengaruhi (interdependent) dan integrasi tidak dapat dilakukan proses perubahan berlangsung. Ketertinggalan proses perubahan manusia (aspek sosial) dengan proses קzembąngunan lain (ekonomi \& fisik) menyebabkan disintegrasi dalam proses pemb高ngunan.

\section{METODOLOGI}

Permasalahan disintegrasi pembangunan atas tiga aspek pembangunan ekonomi, diksik Aan sosial, metodologi dilakukan dengan dua pendekatan. Pendekatan pertama yaitu prose perubahan dalam mencapai kesejahteraan (human well-being) dan kedua proses perubăhan (socialization) mengintegrasikan pembangunan sosial (human well-being) ke đạlan'̄eproses perubahan pembangunan ekonomi dan fisik.

\section{Pendekatan Konsep Human Well-being}

( Perubahan sebagai dinamika kehidupan yang selalu dihadapkan kepada perubahan 庐ngk伭gan yang terjadi namun sulit untuk dilaksanakan dan tidak jarang perubahan sedang Eerlangsungpun sering mendapat tantangan. Perilaku yang terjadi (kelihatan) adalah hasil 烈iba志 analisis terhadap situasi secara keseluruhan (termasuk bagian-bagian atau komponen) antara kondisi nyata individu di dalam situasi kondisi nyata yang dihadapinya.

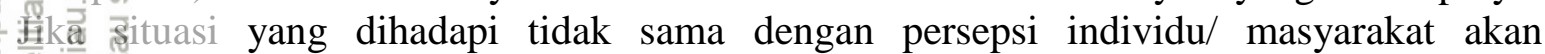
mefrimbulkan rasa kekwatiran atau rasa takut yang kemudian individu melakukan jen lakkan (resistensi). Atas dasar ini Lewins's (Hall \& Lindzey, 1970) memperkenalkan ștatu konsep perubahan yaitu 'unfreeze-change-refreeze.' Unfreeze (mencairkan

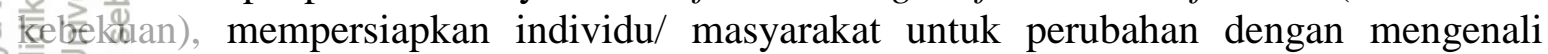
area/orgian yang dipandang perlu untuk ditingkatkan dan perubahan dapat dimulai dari bagia tersebut. Bagian-bagian tersebut dapat berupa hasrat untuk berubah, keuangan yang

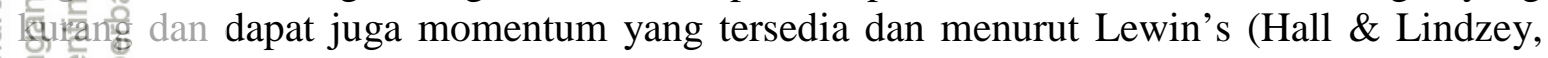
(9) gerethan), perubahan dapat dilakukan melalui solusi-solusi yang tersedia (yang telah As ersiapkan) bagi memecahkan permasalahan yang telah dirumuskan pada tahap jeinearan (unfreeze). Refreeze, jika individu telah menguasai keterampilan baru dan 角e Sole

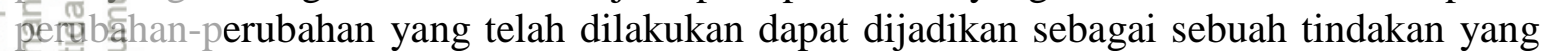
terpola di dalam masyarakat (way of life). Lewin's (Hall \& Lindzey, 1970) menyebut : thathini adalah kunci untuk memastikan permasalahan yang terjadi sebelumnya tidak akan

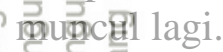

잉 bagaimana proses perubahan ini berlangsung, dapat dipahami melalui suatu model proses perubrihan. Ross (Beckhard, 1969) merumuskan model perubahan dan proses perubahan 
têrsebut yaitu denial, anger, bargaining, depression dan acceptance. Model perubahan Ross banyak digunakan oleh bidang business dan management, dan urutan lebih बiisederhanakan (sesuai dengan tujuan dan kepentingan) yaitu, denial, resistance, exploration dan acceptance or commitment. Umumnya model perubahan Ross yang ⿶imodifikasi pada dasarnya tetap sama dan yang berbeda hanyalah pada terminologinya. Secara garis besar model perubahan Ross dapat lihat dalam empat tahap yaitu resistance, acceptance, commitment dan interaction. Resistance, di awal perubahan pada tahap ini 蛋rjadökekagetan (shock) yang menimbulkan perasaan takut (fear) dan marah (anger) dan 㲖elahiskan penyangkalan (denial). Acceptance, pada tahap ini terjadi tekanan (depression) ⿶ari kondisi lingkungan menyebabkan timbul peluang untuk tawar menawar (bargaining) 霜焦ehamai (understanding) manfaat perubahan yang terjadi. Commitment, proses Perubghan lingkungan diikuti oleh segenap individu (participance) dan mereka secara gersama melakukan perubahan. Terakhir adalah tahap interaction, tahap ini merupakan pruncak dari proses perubahan namun pada tahap ini tidak dapat dilepaskan begitu saja sebaborubahan yang sudah berlangsung belum tentu telah merubah value yang ada di dalam masyarakat. Untuk itu perlu dilakukan keberlanjutan (sustainable) agar perubahan Fang delah dicapai akan tetap terus dan tidak kembali kepada persoalan semula. Oleh Eewing s proses perubahan akhir ini disebut dengan tahap refreeze.

\section{Rendëkatan Konsep Integrasi Socialization}

Bertolak dari tiga fase dasar perubahan sosialisasi (Water \& Crook dalam Syarif), fase kêluarga (primer), lingkungan (sekunder) dan lingkungan sosial yang baru (tersier).

Sebagi makhluk biologis individu memerlukan pemenuhan kebutuhan biologis (makan, 南inu侕 dsb) dan beraksi terhadap stimulus dari lingkungannya. Bereaksi dan stimulus dengân lingkungan merupakan proses berinteraksi atau dengan kata lain individu telah mengälami proses sosialisasi, dan selanjutnya akan berkembang menjadi makhluk sosial.

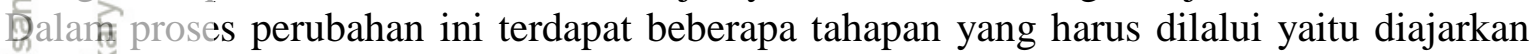

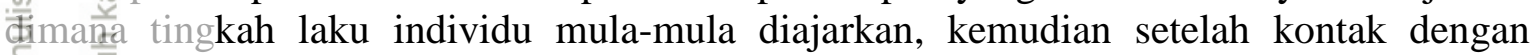
造nk出gan mereka akan memilih dan menentukan sendiri keinginan mereka. Ketika i⿺辶寸divin berada di tempat-tempat atau lingkungan yang baru mereka akan berinteraksi dan

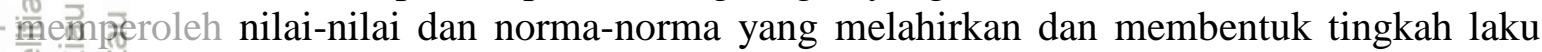

Dalam proses sosialisasi terdapat tiga proses agar seorang individu ataupun 舟asy prosespenguatan.

Meniru merupakan proses yang fundamental dalam sosialisasi, dimana proses ini 1metho pengamatan terhadap cara orang lain bertingkah laku, dan kemudian merekam

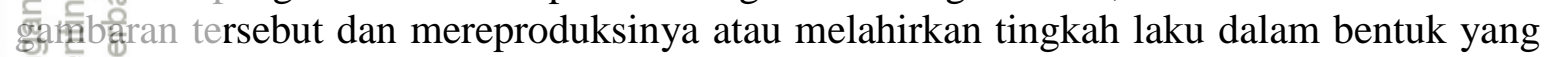
serapa Proses peniruan sangat efektif sekali untuk merubah tingkah laku individu. Eenga natan (objek yang akan ditiru), tindakan pengulangan yang sama, namun pada tahap Per⿳亠⿴囗十⺝⿱ sectrie simultan agar hasil akhir sama dengan objek yang ditiru sebagaimana yang 由icon

잘 Generalisasi merupakan proses pembentukan identitas diri, proses ini terbentuk dan ger

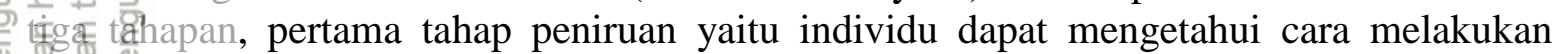
sestat dengan meniru tindakan individu yang dekat dengannya. Tahapan ini belum wemerikan makna apapun terhadap tingkah laku yang ulang dari individu lain dan hanya 垔 idivio mulai mengenal makna atas tingkah laku yang dilakukan dengan memainkan - perankepada lingkungannya. Peranan yang dimainkan yaitu bertindak memerintah atau 
thelarang namun individu belum memiliki konsep diri dan peran tersebut hanya mengikuti a tau mengambil peran yang dilakukan oleh individu lain. Tahapan ini disebut juga sebagai öroses pengalihan karakter dari luar diri ke dalam kepribadiannya. Tahapan ketiga mengonseptualisasikan dirinya secara keseluruhan yaitu mampu menentukan tindakan ging seharusnya dilakukan dalam lingkungannya. Tahapanini individu mengetahui norma范orma yang berlaku di dalam lingkungan dan memiliki peranan sendiri di dalamnya.

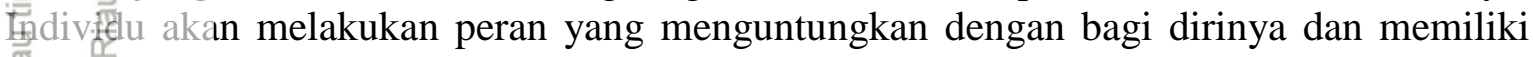
Potensi di dalam lingkungan serta mencari potensi yang berbeda (tidak meniru individu).

Proses penguatan terjadi dengan mengulang-ulang tingkah laku secara simultan dan dalam proses pengulangan diwarnai dengan oleh dinamika reward dan punishment dari 离 茴 Punistament dari lingkungan maka individu akan mengokersi tingkah laku yang dilakukannya dan demikian seterusnya sehingga individu secara totalitas masuk ke dalam

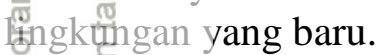

Eata

Objek studi adalah sosialisasi studi Upaya Pengelolaan dan Upaya Pemantauan Eingkengan (UKL-UPL) Jembatan Layang Lubuk Buaya Kota Padang. Kegiatan ini 䄵erupakan pembangunan dan peningkatan infrastruktur jalan (transportasi) terutama di forkskan kepada kelancaran lalu lintas jalan raya. Jembatan akan dibangun pada jalur lalu 广intas 送eret Api. Secara langsung kegiatan ini tidak memberikan dampak, namun secara tidak

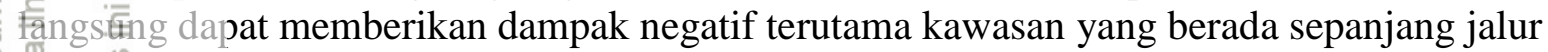
جaitu角enurunan kualitas lingkungan. Penurunan kualitas dapat mencakup aspek ekonomi (erdägangan), fisik (performance fisik) dan sosial (pemisahan strata).

\section{HASIL}

Fokus lingkungan tidak lain adalah permasalahan yang ditimbulkan oleh kegiatan pirose pembangunan. Pembangunan dan lingkungan ibarat dua sisi mata uang, dia tidak

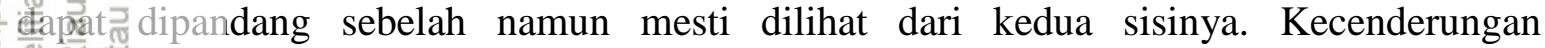
peffibangunan (aspek ekonomi, aspek sosial dan aspek fisik) masa lalu telah menimbulkan pene

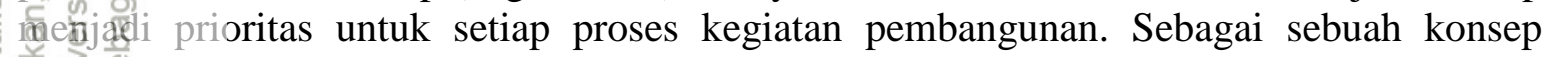
peläbangun berkelanjutan, prosesnyatidaklah bersifat linear tetapi membentuk sirkel (eycles) yang menuju kepada suatu tujuan pembangunan yang ideal (human well-being).

을 Atas dasar kesadaran pentingnya untuk menjaga kelestarian lingkungan 'hidup' ini, 结禹兽nuncul/ lahir aspek baru disamping aspek-aspek yang telah ada yaitu memasukan aspék lingkungan menjadi bagian aspek pembangunan. Dalam susunan kerangka técoterkal, aspek-aspek pembangunan dapat berperan sebagai variabel yang mana aspek \& or momi merupakan variabel bebas yang merupakan juga sebagai alat (tools) dalam Pei $b$ qngun. Sementara aspek sosial, lingkungan hidup, fisik dan pembangunan berperan sébä gariabel interveing dan terakhir adalah (pembangunan) kebelanjutan merupakan Ravival tergantung.

을 둥 을 trefet : Partalgel pembangunan dapat menjelaskan peranan dari masing-masing aspek dalam proses perabongun. 


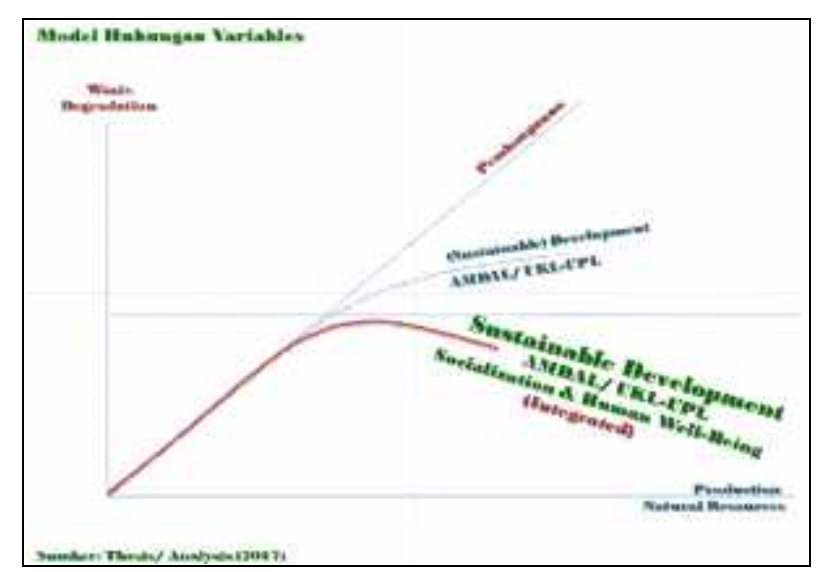

G (sumber: Analisis, 2017)

\section{PEMBAHASAN}

Pembangunan Jembatan Layang adalah memperlanjar arus lalu lintas dan 壖ening katkan mobilisasi barang dan orang dari satu Kota Padang ke luar kota dan sebal ${ }^{1}$ nya. Kelancaran lalu lintas ini tentu ditujukan kepada pengguna jalan (kendraan sermoror) dan berkontribusi menghindarkan kemacetan yang cenderung merusak

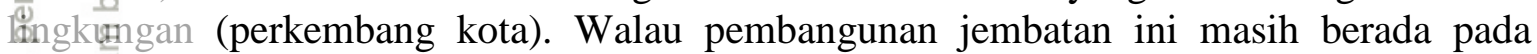
tanhan $\frac{\pi}{\mathrm{N}}$ alur jalan (tidak mengambil lahan masyarakat namun tetap memberikan dampak egatif kepada lahan-lahan (ruko sepanjang jalur) yaitu telah mempersempit ruang terbuka (kualinas udara) yang ada di depan bangunan ruko. Artinya secara kualitas lingkungan telah 商engami penurunan (degradation) yaitu memperkecil volume udara yang ada di depan bangưnan di sepanjang jalan tersebut.

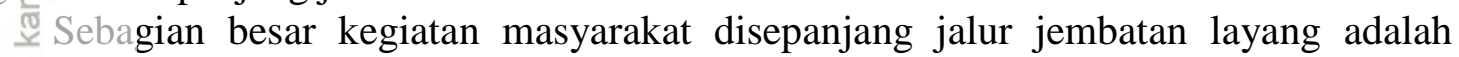
gedagang (rumah \& toko atau ruko) danpara pedagang menawarkan material bagi sebagian pengtini kawasan dan sebagian lagi bagi para pengendara yang melintas di jalurtersebut. Fierek8nomian secara makro memang memberikan potensi untuk Kota Padang namun seara mikro akan mengurangi jumlah transaksi di sepanjang jalur tersebut. Kecuali bagi perygendara yang membutuhkan sesuatu akan turun (tidak melintasi jalur jembatan atau tetap berada pada jalur yang lama). 2erbâh pertama cara pandang mereka yaitu tidak lagi bergantung dengan mata perge arian lama namun mulai melihat peluang baru dari dampak positif pembangunan.

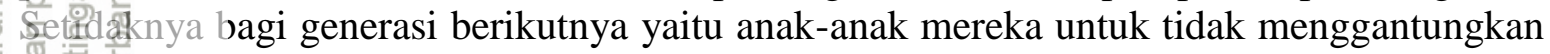

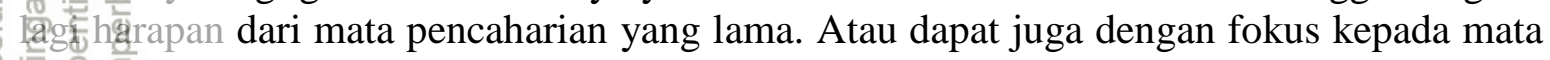

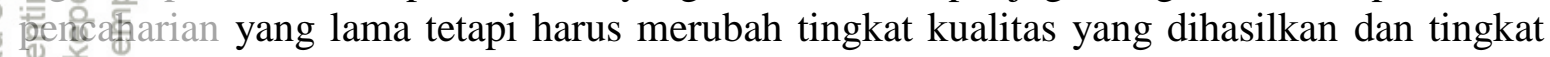
i i clisesuaikan dengan tuntutan lingkungan. Penting disini adalah merubah cara pandang (rire do $\mathrm{m}$ of choice and action). Jika perubahan ini dapat dilakukan selanjutnya akan masuk

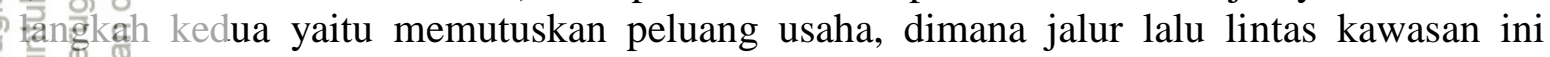
ad면at jalur utama menuju bandar udara maka peluang usaha yang dapat mereka pilih atlofalatis sektor keparawisataan (sovenir-kuliner dsb.) dengan kualitas global. Peningkatanpeling garic Eingkat propinsi ataupun tingkat kota serta dukungan peningkatan modal melalui

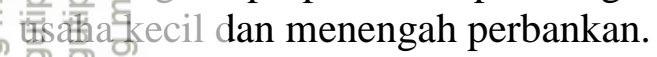

든 (betpindah) masyarakat menjadi masyarakat global dapat diwujudkan setelah mereka dapat dirutibah menjadi aman (secure, good health, penghasil cukup serta hubungan sosial yang baik). 


\section{KESIMPULAN DAN SARAN}

Sosialisasi merupakan suatu proses merubah masyarakat dari cara pandang dan cara lịidup lama menuju ke cara baru dan ini hanya dapat dilakukan melalui pembangunan sosial. Kegiatan AMDAL tidak punya kredibilitas untuk melakukan proses sosialisasi, dan AMAL hanya menganalisis kemungkinan dampak negatif suatu pembangunan terhadap 蕾nkungan serta berupaya untuk meminimalkan risiko baik melalui analisis, pengelolaan Gan permantauan lingkungan.

을 Proses sosialisasi yang selama ini dilakukan dalam kegiatan AMDAL adalah Femberritahuan kepada masyarakat terhadap rencana pembangunan dan AMDAL atau lebih

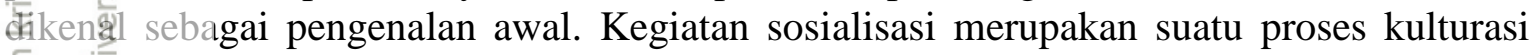

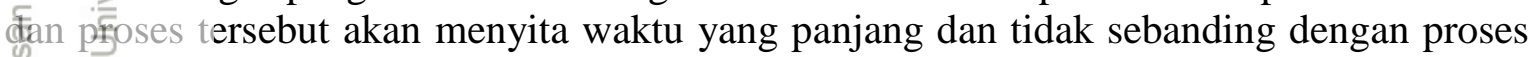
AMAL dengan waktu yang singkat.

\section{DAFTAR PUSTAKA}

Geckinard, R (1969). Organization Development: Strategies and Models. Addison-Wesley, Reading, MA.

Serged, Peter L. \& Thomas P. Luckman (1967). The Social Construction of Reality. Penguin Books. Great Britain.

Berger, Peter L. (1984). Invitation to Sociology: A Humanistic Perspective. Penguin Books. USA.

Bernat: H. Russell. (1994). Research Methods in Anthropology: Qualitative and $\overline{\frac{\pi}{0}}$ Quantitative Approaches. Sage Publication. California.

Ẽampīَell, Ernest Q. (1975). Socialization: Culture and Personality. WM. C.Brown 咭 Company Publishers. USA.

Eooley, Charles Horton. (1956). Human Nature and Social Order. Free Press. Glencoe.

New York.

Ëanziger, Kurt. (1971). Socialization. Penguin Books Ltd.. Australia.

Q 2 enzi⿱⺈, Norman K. (1977). Childhood Socialization: Studies in the Development of

is Language, Social Behavior and ldentity. Jossey-Bass Publishers. San Francisco.

être Hildred (1961). The Javanese Family: A Study of Kinship and Socialization. The

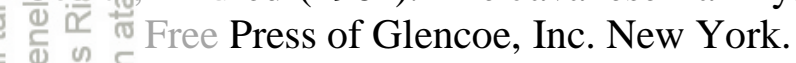

Gilsor, Janice T. (1978). Growing up: A Study of Children. Addison-Wesley Publishing

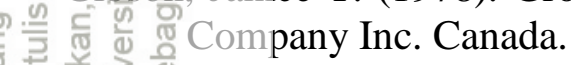

音勘, S. \& Lindzey, G (1970). Theories of Personality. New York: Wiley.

Handeral, Gerald. (1988). Childhood Socialization. Aldine De Gruyter. New York.

Hafil Jonathan M. (2000). Basic Principles of Sustainable Development. Tufts 䎡

具e落遗, Stepanus (2013). Partisipasi Masyarakat Dalam Pembangunan Di Kelurahan

Sungai Keledan Kecamatan Samarinda Seberang Kota Samarinda. E-Journal Ilmu

(1) Pemerintahan. Vol. 1 No. 2. 612-625.

尊uesman, L. Rowell \& Leonard D. Eron. (1986). Television and the Aggressive Child:

Across National Comparison. Lawrence Erlbaum Associates. London.

Eo Press. Chicago.

Kugtjăraninggrat (1994). Kebudayaan Mentalitas dan Pembangunan. PT. Gramedia 을 uㅗㄹ.

Oscar (1959). Five Families: Mexican Case Studies in the Culture of Poverty. Basic

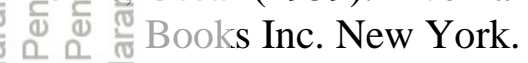

Mla

PT. Bina Aksara. Jakarta. Indonesia. 
Mlardijani, Prastiwi (2010). Pertisipasi Masyarakat terhadap Peningkatan Pembangunan

Desa. Journal Buletin Ekonomi. Vol 8. No. 1, April 2010 Hal. 1-70.

Matsuura, Koichiro (2000). Why Languages Matter. Meeting millennium development goals through local languages. UNESCO.

ज्ञlead, George Herbert (1956). On Social Psychology: Selected Papers. University of Chicago Press. Chicago.

ㄱasumon, M. Nur. (2010). Manajemen Perubahan. Ghalia Indonesia. Jakarta.

Yasution, Zulkarimen (2007). Komunikasi Pembangunan (Pengenalan Teori dan

Penerapannya). Penerbit PT Raja Grafindo Persada : Jakarta.

甘drale, Taliziduhu (1988). Pembangunan Masyarakat. Jakarta. Indonesia.

Fiarke Ross D. (1981). Fathers. Harvard University Press. Cambridge.

Prasoj, Eko (2003). People and Society Empowerment: Perspektif membangun partisipasi public. Resume hasil penelitian penulis dan tim Pusat Kajian Strategi Pembangunan Sosial dan Politik (PKSPSP) FISIP UI dalam literature research dengan judul "Pola dan Mekanisme Pemberdayaan Masyarakat di DKI Jakarta.

Rober

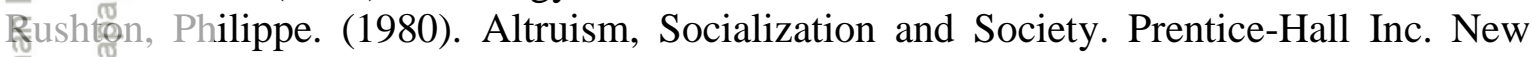
Jersey.

Sairin Sjafiri (2002). Perubahan Sosial Masyarakat Indonesia. Perspektif antropologi. Penerbit Pustaka Pelajar. Yogyakarta. Indonesia.

Simmêl, Georg (1986). Beberapa Teori Sosiologis. CV. Rajawali. Jakarta. Indonesia.

Spiro Melford E. (1972). Children of the Kibbutz. Schocken Books. New York.

Surosī, Hadi dkk. (2014). Faktor-Faktor yang Mempengaruhi Partisipasi Masyarakat

을 dalam Perencanaan Pembangunan di Desa Banjar Kecamatan Driyorejo Kabupaten

Gresik. Journal Wacana. Vol. 17. No. 1. Hal 7-15.

焉aylow \& Francis (2016) Community Development. Publishes with Routledge.

http://www.tangdfonline.com/toc/rcod20/current

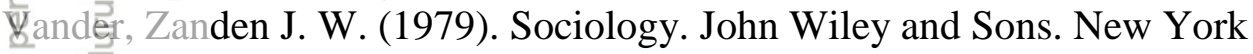

Wate Malcolm \& Rodney Crook. (1946). Sociology One: Principle of Sociological

远

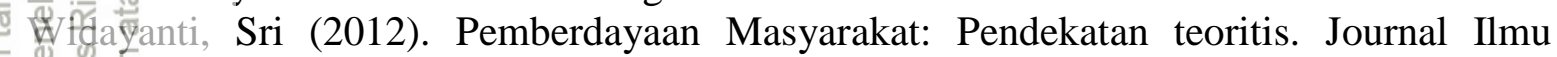
Kesejahteraan Sosial. Vol. 1 No. 1 Hal. 87-102.

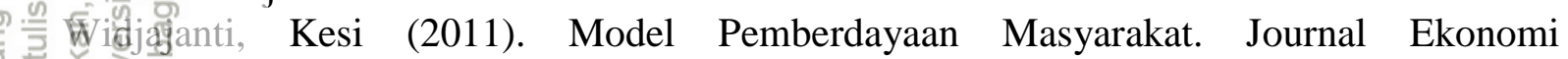
일 i Pembangunan. Vol. 12 No. 1 15-27.

Wi iaredia (2016) Participatory Development

Airecr, David (1994). Summary, Community Participation and Empowerment. Joseph

政

造Bank (1999). Community Participation. Understanding community participation. 